\title{
Effect of exosomes from plasma of dairy cows with or without an infected uterus on prostaglandin production by endometrial cell lines
}

\author{
Fatema B. Almughlliq, ${ }^{*}$ Yong Q. Koh, ${ }^{*}$ Hassendrini N. Peiris, ${ }^{*}$ Kanchan Vaswani, ${ }^{*}$ Scott McDougall, $\dagger$ \\ Elizabeth M. Graham, $\dagger$ Chris R. Burke, $\ddagger$ and Murray D. Mitchell*1 \\ *University of Queensland Centre for Clinical Research, The University of Queensland, Brisbane, Queensland, 4029, Australia \\ †Cognosco, Anexa FVC, Morrinsville 3340, New Zealand \\ ‡DairyNZ Ltd., Private Bag 3221, Hamilton 3240, New Zealand
}

\section{ABSTRACT}

A contributing factor to declining fertility in dairy cows is an activated inflammatory system associated with uterine infection. Detecting uterine disease using biomarkers may allow earlier diagnosis and intervention with resultant improvements in fertility. Exosomes are known to participate in intercellular communication, paracrine, and endocrine signaling. Exosomes carry a cargo of proteins, lipids, and nucleic acids that represent specific cellular sources. Prostaglandins are lipids that are critical determinants of bovine fertility. In this study exosomes were isolated from the plasma of cows before (d 0) and during (d 10) the study in healthy animals or those with an induced uterine infection in a $2 \times 2$ factorial design. Exosomes were characterized for size and number (nanoparticle tracking analysis), exosomal marker expression (Western blot), and morphology (transmission electron microscopy). No significant differences were observed in exosome size or number. The abundance of exosome-enriched markers was confirmed in noninfected and infected animals. Transmission electron microscopy confirmed the morphology of the exosomes. These exosomes were co-incubated with bovine endometrial epithelial and stromal cells. Exosomes from d-10-infected animal plasma decreased $\mathrm{PGF}_{2 \alpha}$ production in endometrial epithelial but not stromal cells. For future research, the identification of effectors in the cargo may provide a useful basis for early diagnosis of uterine infection using an exosomal characterization approach.

Key words: dairy cow, uterine infection, exosome, prostaglandin

Received May 31, 2017.

Accepted July 21, 2017.

${ }^{1}$ Corresponding author: murray.mitchell@uq.edu.au

\section{INTRODUCTION}

Maintaining optimal reproductive performance is an important economic driver in dairy cattle production. Poor reproductive performance is associated with extended intervals between calvings, reduced milk production, and increased risk of cows being removed from the population, and thus significant economic losses (Inchaisri et al., 2010). Improved management has increased milk production, but fertility has declined due to increased metabolic pressure (Lucy, 2001; Garnsworthy et al., 2008; Roche et al., 2011).

Bacteria can be isolated from the majority of cows in the early postpartum period. However, many of these infections are self-limiting, but clinical disease is associated with the ongoing presence of Escherichia coli, Trueperella pyogenes, Prevotella spp., Fusobacterium spp., or Bacteroides spp. (Sheldon et al., 2002). Prevalence of clinical endometritis (presence of grossly evident purulent material in the vagina or uterus) is estimated to be 15 to $20 \%$ in dairy cows, and $30 \%$ are affected by subclinical endometritis (inflammation of the uterus as determined using cytology; Sheldon et al., 2009). Uterine inflammation, whether it is grossly evident or not, is associated with decreased conception rates and prolonged days to first service and days open, and it has been demonstrated that subclinical endometritis has an effect on survival and quality of the embryo (Kasimanickam et al., 2004; McDougall et al., 2011; Ribeiro et al., 2013).

Uterine disease is currently diagnosed using cow-side tests, such as gloved hand examination of the vaginal contents, vaginoscopy, use of an intravaginal probe to retrieve purulent material (Metricheck device, Simcro, Hamilton, New Zealand), or endometrial cytology among others (de Boer et al., 2014). Although endometrial cytology appears to have a higher sensitivity than other tests (McDougall et al., 2011), and is a better predictor of reproductive performance than other tests, it is an expensive and time-consuming test that re- 
quires laboratory infrastructure. Sensitive and specific, rapid, and cost-effective diagnostic tools for uterine disease need to be developed in dairy cattle, potentially through the use of biomarkers.

Exosomes are highly stable extracellular vesicles (EV) that bud from the cell membrane and are 30 to $120 \mathrm{~nm}$ in diameter (Raposo and Stoorvogel, 2013; Sohel et al., 2013). They are involved in cell-to-cell communication and may be useful in diagnosis of several biological conditions (Crookenden et al., 2016; Mitchell et al., 2016). Exosome number and content are altered under physiological pressures (e.g., cancer, pregnancy, and infection; Sabapatha et al., 2006; Silverman et al., 2010; King et al., 2012) and have a role in immunomodulation (Deng et al., 2013). Prostaglandins (PG), as well as being immunomodulatory agents, are key players in bovine fertility. Prostaglandin $\mathrm{F}_{2 \alpha}\left(\mathrm{PGF}_{2 \alpha}\right)$ and prostaglandin $\mathrm{E}_{2}\left(\mathbf{P G E}_{\mathbf{2}}\right)$ are the main $\mathrm{PG}$ associated with reproduction. The endometrium release of $\mathrm{PGF}_{2 \alpha}$ initiates luteolysis, and $\mathrm{PGE}_{2}$ is a temporary luteotrophic signal, acting with interferon $\tau$, for pregnancy maternal recognition (Arosh et al., 2002). During uterine infection in postpartum cows, plasma concentrations of $\mathrm{PGF}_{2 \alpha}$ metabolite are increased (Del Vecchio et al., 1994). In vitro studies of endometrial cells have shown PG are produced at differing rates. Stromal cells produce more $\mathrm{PGE}_{2}$ than epithelial cells, with a reversal for $\mathrm{PGF}_{2 \alpha}$ (Fortier et al., 1988; Danet-Desnoyers et al., 1994; Asselin et al., 1996), whereas in another report secretion of PG was similar by epithelial and stromal cells (Betts and Hansen, 1992). Endometrium explants or cell lines challenged with LPS produced higher $\mathrm{PGE}_{2}$ compared with $\mathrm{PGF}_{2 \alpha}$ (Herath et al., 2009).

This study aimed to assess whether the number or size of exosomes isolated from the plasma of cows with and without infection of the bovine uterus is altered, and furthermore, whether plasma exosomes from these cows could change PG production by endometrial cells.

\section{MATERIALS AND METHODS}

\section{Animals}

This negative controlled intervention study was conducted using 20 cows collected at d 0 and 10 sourced from a single research herd located in the north of New Zealand (Lye Farm, DairyNZ Vaile Rd., Newstead). Cows were selected based on calving date, freedom from grossly evident peripartum disease, and not having been treated with antimicrobials or nonsteroidal anti-inflammatories in the $14 \mathrm{~d}$ preceding the commencement of the study.

Cows were synchronized using the G-6-G/OvSynch protocol (that is a sequence of $\mathrm{PGF}_{2 \alpha}, \mathrm{GnRH}, \mathrm{GnRH}$,
$\mathrm{PGF}_{2 \alpha}$, and $\mathrm{GnRH}$ at 2-, 6-, 7-, and 2-d intervals, respectively; Bello et al., 2006), and all cows were treated with an intrauterine antimicrobial (0.5 g of cephapirin, Metricure, MSD, Upper Hutt, New Zealand) at the time of the first GnRH injection.

At $96 \mathrm{~h}$ after the final GnRH of the synchrony protocol (i.e., approximately $3 \mathrm{~d}$ after ovulation), cows were blocked by age $(2,3$, greater than $3 \mathrm{yr})$ and then randomly assigned to 2 groups ( $\mathrm{n}=18$ per group). Half the cows were infused with saline, and the remaining half were further randomly (within age) assigned into 2 groups and infused into the uterus with either a dose of $10^{7} \mathrm{cfu}$ or $10^{9} \mathrm{cfu}$ of $T$. pyogenes. The strain of $T$. pyogenes and the technique of infusion was the same as that used by Amos et al. (2014).

Prior to infusion, and at d 10 after infusion, duplicate swabs were collected from the body of the uterus using triple guarded uterine catheters. One swab was used to prepare a glass slide for subsequent staining and cytological evaluation (Kasimanickam et al., 2004), and the second was placed in transport media for aerobic and capnophilic bacterial culture. The cows were observed daily for signs of clinical disease including increased rectal temperature, a drop in milk yield, and systemic signs of illness (dullness, dehydration, and so on), and daily transrectal ultrasonography to assess ovarian follicle development was undertaken. Blood samples $(8 \times 10 \mathrm{~mL}$ of EDTA, $2 \times 10-\mathrm{mL}$ plain vacutainers $)$ were drawn on the days of uterine sampling from a jugular vein. Plasma progesterone was determined by a validated RIA (ImmunoChem Double Antibody Progesterone RIA Kit from MP Biomedical, Santa Ana, CA, catalog \# 07-170105; https://www.mpbio .com/product.php?pid=07170105) in the laboratory of DairyNZ (Newstead, New Zealand). The minimum detectable concentration was $0.18 \mathrm{ng} / \mathrm{mL}$. The within and between assays coefficients of variation were $2.3 \%$ and $5.2 \%$ for the high $(2.1 \pm 0.1 \mathrm{ng} / \mathrm{mL}$; mean $\pm \mathrm{SD})$ and $3.9 \%$ and $10.0 \%$ for the low $(0.25 \pm 0.03 \mathrm{ng} / \mathrm{mL})$ quality assurance standards, respectively.

Following culture, plasma from a subset of 10 cows from the control group with no evidence of infection and 10 cows from the T. pyogenes-treated group, in which heavy bacterial infection was confirmed by culture, were selected for this current study. These cows were all $>12 / 16$ ths Holstein-Friesian, averaged $2.7 \mathrm{yr}$ of age ( $\mathrm{SD}=0.9$; range 2 to 4$)$, and were an average of $48.2 \mathrm{DIM}(\mathrm{SD}=4.1$; range 43 to 58 ) at the time of intrauterine challenge. Cows had an average BW of 422 $\mathrm{kg}(\mathrm{SD}=47$; range $360-526 \mathrm{~kg})$ and a BCS of 4.1 (SD $=0.2$; range $3.75-4.5 \mathrm{BCS}$; on a 1 to 10 scale, Roche et al., 2004) at 5 d before intrauterine challenge. Average daily milk yield over the $7 \mathrm{~d}$ preceding challenge was $21.2 \mathrm{~L} /$ cow per day $(\mathrm{SD}=2.8$; range $18.0-27.0$ 
$\mathrm{L} /$ cow per d). Cows were fed on pasture that was predominantly ryegrass (Lolium perenne) and white clover (Trifolium repens), with a new area of pasture offered every $12 \mathrm{~h}$.

\section{Bacterial Culture of Uterine Swabs}

Uterine swabs were transported to the laboratory on the day of collection. On arrival, swabs were plated onto Columbia agar containing $5 \%$ sheep blood, MacConkey agar, and Columbia CNA agar (Fort Richard Laboratories, Auckland, New Zealand). All culture plates were incubated at $37 \pm 1^{\circ} \mathrm{C}$ for up to $48 \mathrm{~h}$. Columbia agar containing $5 \%$ sheep blood and MacConkey plates were incubated in air, and CNA plates were incubated under capnophilic conditions. Suspected T. pyogenes isolates were submitted externally for identification by MALDI-TOF (PathLab, Tauranga Hospital Campus, Tauranga, NZ).

\section{Endometrial Cell Culture}

Bovine stromal and epithelial cell lines were kind gifts from Michel A. Fortier (Université Laval, Québec, Canada). Cells were not deposited with the American Type Culture Collection. They were grown in RPMI medium (Gibco, Thermo Fisher Scientific Australia Pty. Ltd., Scoresby, Vic, Australia) containing exosome depleted $10 \%$ fetal bovine serum (Bovorgen, Interpath Services Pty. Ltd., Heidelberg West, Vic, Australia) and 1,000 $\mathrm{U} / \mathrm{mL}$ antibiotic-antimycotic solution (Gibco, Thermo Fisher Scientific Australia Pty. Ltd.) and incubated at $37^{\circ} \mathrm{C}$ and $5 \% \mathrm{CO}_{2}$ (Asselin et al., 1996). Experiments were conducted in media without fetal bovine serum.

\section{EV Isolation from Plasma by Ultracentrifugation}

Extracellular vesicles were isolated from 40 plasma samples by successive differential centrifugation steps, conducted as previously described (Mitchell et al., 2016). Briefly, the plasma was centrifuged $\left(4^{\circ} \mathrm{C}\right)$ at $2,000 \times g$ for $30 \mathrm{~min}$ and then $12,000 \times g$ for $30 \mathrm{~min}$. The supernatant was filtered using a $0.22-\mu \mathrm{m}$ filter, and then it was ultracentrifuged at 100,000 $\times g$ for $2 \mathrm{~h}$ at $4^{\circ} \mathrm{C}$ using a fixed angle ultracentrifuge rotor Type $70.1 \mathrm{Ti}$ (Beckman Coulter, Brea, CA). The 100,000 $\times g$ pellet $(\mathrm{EV})$ was reconstituted in $500 \mu \mathrm{L}$ of PBS (Gibco, Thermo Fisher Scientific Australia Pty Ltd.) and stored at $-80^{\circ} \mathrm{C}$.

\section{Exosome Separation and Purification by Size Exclusion Columns}

Extracellular vesicles obtained from ultracentrifugation were loaded onto $\mathrm{qEV}$ size exclusion columns
(Izon, Oxford, UK) for exosome isolation, as per manufacturer instructions. This technique allows the separation of particles from EV pellet based on their size into 16 fractions. The 16 fractions were concentrated using a vacuum concentrator for $1.5 \mathrm{~h}$ at room temperature.

\section{Protein Quantification}

Protein concentration of exosomal fractions was quantified by a bicinchoninic acid assay (Sigma-Aldrich, St. Louis, MO) and BSA (Sigma-Aldrich) as standards.

\section{Immunoblotting}

Exosomes $(10 \mu \mathrm{g}$ of protein) were further characterized using gel electrophoresis (NuPAGE Novex 4-12\% Bis-Tris, Thermo Fisher Scientific Australia Pty. Ltd.) for confirmation of exosomal markers flotillin 1 and tumor susceptibility gene 101. The gel was then transferred to a PVDF membrane (Bio-Rad Laboratories Pty. Ltd., Gladesville, New South Wales, Australia) using Trans-Blot Turbo system (Bio-Rad Laboratories Pty. Ltd.). After blocking (5\% skim milk powder), membranes were probed overnight with primary antibodies anti-flotillin 1 (Abcam, Cambridge, UK) and anti-tumor susceptibility gene 101 (Abcam) at $4^{\circ} \mathrm{C}$, followed by secondary anti-rabbit IgG (Sigma-Aldrich) and secondary anti-goat (Sigma-Aldrich), respectively. Membranes were then covered with SuperSignal West Dura-Extended Duration Substrate (Thermo Fisher Scientific Australia Pty. Ltd.). Targeted proteins were visualized on x-ray films using a Konica SRX101A processor (Konica Minolta Inc. Medical and Graphic, Tokyo, Japan).

\section{Transmission Electron Microscopy}

Transmission electron microscopy was used to visualize exosome particles from exosomal fractions. A total of $5 \mu \mathrm{L}$ of sample was added onto formvar-coated copper grids for 2 min and then briefly washed in ultrapure water and negatively stained with $1 \%$ uranyl acetate. The samples were than visualized using the JEOL 1010 transmission electron microscope (JEOL Ltd., Tokyo, Japan) operated at $80 \mathrm{kV}$, and images were captured using an Olympus Soft Imaging Veleta digital camera (Olympus, Center Valley, PA).

\section{Nanoparticle Tracking Analysis}

Based on the presence of exosomal biomarkers by immunoblotting, exosomal fractions (10 to 16) were pooled for nanoparticle tracking analysis (NTA) measurements using a NanoSight NS500 instrument (Nano- 
Sight NTA 3.0 Nanoparticle Tracking and Analysis Release Version Build 0064, Malvern, Malvern, UK) as previously described (Mitchell et al., 2016).

\section{Co-Incubation of Exosomes with Endometrial Cells}

Bovine stromal cells (seeding density of 8,000 cells per well) and bovine epithelial cells (seeding density of 35,000 cells per well) were incubated for $24 \mathrm{~h}$, grown in RPMI media (Gibco, Thermo Fisher Scientific Australia Pty. Ltd.) containing exosome depleted $10 \%$ fetal bovine serum (Bovorgen, Interpath Services Pty. Ltd.) and $1,000 \mathrm{U} / \mathrm{mL}$ antibiotic-antimycotic solution (Gibco, Thermo Fisher Scientific Australia Pty. Ltd.). For the coculture experiment (treatment with exosomes), fetal bovine serum-free RPMI media, containing 1,000 $\mathrm{U} / \mathrm{mL}$ antibiotic-antimycotic solution (Gibco, Thermo Fisher Scientific Australia Pty Ltd.), was used. From our preliminary results, we determined the time of incubation based on a time course experiment that we carried out for both cell lines, where we stimulated the cells with LPS, tumor necrosis factor $\alpha$, or IL- $1 \beta$ over a period of 12, 24, and $48 \mathrm{~h}$. Our results showed that the optimal response to the 3 different stimuli was at $24 \mathrm{~h}$; therefore, in the current study we collected media after $24 \mathrm{~h}$ of co-incubation. Exosomal dosage was chosen in reference to literature (Franzen et al., 2014). Cells were incubated with RPMI media with no addition of exosomes (No EXO control, for baseline measurements) or treated with plasma exosomes $\left(1 \times 10^{8}\right.$ particles per well) derived from the 4 groups [10 control and 10 infected animals, sampled at 2 time points (d 0 and 10)] for $24 \mathrm{~h}$ at $37^{\circ} \mathrm{C}$ and $5 \% \mathrm{CO}_{2}$. We performed 2 well replicates per individual cow at $\mathrm{d} 0$ and $10(\mathrm{n}=40)$. Cell culture experiments were performed in duplicate per cell line. Media was collected and stored at $-80^{\circ} \mathrm{C}$ until required for further analyses.

\section{Measurement of PG Production by ELISA}

Prostaglandins $\mathrm{PGF}_{2 \alpha}$ and $\mathrm{PGE}_{2}(\mathrm{pg} / \mathrm{mL})$ were measured directly from cell culture media using ELISA kits (Cayman Chemicals, Ann Arbor, MI) according to the manufacturer instructions. The $\mathrm{PGF}_{2 \alpha}$ assay has a sensitivity of $10 \mathrm{pg} / \mathrm{mL}$, and the $\mathrm{PGE}_{2}$ assay has a sensitivity of $30 \mathrm{pg} / \mathrm{mL}$. Both assays had intra-assay variation of $10 \%$ per the manufacturer's description.

\section{Measurement of IL-6 Production by ELISA}

The production of IL-6 (ng/mL) was measured directly from cell culture media using a Bovine IL-6 ELISA Kit (Abcam) according to the manufacturer's instructions. The assay has a sensitivity of $0.03 \mathrm{ng} / \mathrm{mL}$ and had intra-assay variation of $10 \%$ per the manufacturer's description.

\section{Lactate Dehydrogenase Assay}

To determine cell viability and death, lactate dehydrogenase release was measured using the commercially available kit, Pierce LDH Cytotoxicity Assay Kit (Thermo Fisher Scientific Australia Pty. Ltd.), according to the manufacturer's instructions.

\section{Statistical Analyses}

Neutrophil percentage was not normally distributed and, therefore, natural log-transformed after addition of one (to account for $0 \%$ results). Natural log-transformed neutrophil percentage was analyzed by one-way ANOVA before infusion (i.e., d 0) and at d 10 after infusion. Serum progesterone concentrations were analyzed by one-way ANOVA at d 10 after infusion. Additionally, the d-10 progesterone data were categorized into cows unlikely to have ovulated (i.e., progesterone concentrations $\leq 1 \mathrm{ng} / \mathrm{mL}$ ) or to have ovulated (i.e., $>1 \mathrm{ng} / \mathrm{mL}$ ). The difference in proportion ovulating was analyzed by chi-squared between treatment groups. The proportion of animals from which $T$. pyogenes was isolated at d 10 after infusion was analyzed by chisquared, with treatment (i.e., infusion vs. control) as the main effect.

Measurements of $\mathrm{PGE}_{2}$ and $\mathrm{PGF}_{2 \alpha}$ from cocultured media were statistically analyzed using Prism software (prism7, GraphPad Inc., La Jolla, CA). Production of $\mathrm{PGE}_{2}$ and $\mathrm{PGF}_{2 \alpha}$ are presented as means $\pm \mathrm{SEM}$ ( $\mathrm{n}=10$ per group; d 0 noninfected, d 0 infected, d 10 noninfected, and d 10 infected), with comparisons made between groups and basal production from the control data. Nonparametric Kruskal-Wallis one-way ANOVA was used for multiple comparisons between all groups. Wilcoxon matched-pairs signed rank test was used for paired comparison within the same animals of each group (d 0 infected compared with d 10 infected, and d 0 noninfected compared with d 10 noninfected). Statistical significance was defined as $P<0.05$.

\section{RESULTS}

\section{Trueperella pyogenes Infection}

Infected cows had a higher proportion of nucleated cells that were neutrophils upon endometrial cytology than control cows $(30.6 \pm 18.3$ vs. $4.6 \pm 5.0 \%$ PMNL, respectively; $P<0.001$ ).

Trueperella pyogenes was not isolated from any cow before infusion or from control cows at any stage after 
infusion, but it was isolated from all treated cows on d 7 and 10 after infusion (100 vs. 0\% for infected vs. control cows, respectively; $P<0.001$ ).

The Ln PMNL\% did not differ between groups before infusion $(0.4 \pm 0.54$ vs. $0.5 \pm 0.2$ for infected vs. control cows, respectively; $P=0.40$ ). The Ln PMNL\% was higher in infected versus control cows at $\mathrm{d} 10$ after infusion $(3.3 \pm 0.7$ vs. $1.3 \pm 1.0$ for infected vs. control cows, respectively; $P<0.001)$.

Plasma progesterone did not differ as determined on d $10(2.8 \pm 2.6$ vs. $2.3 \pm 1.6 \mathrm{ng} / \mathrm{mL}$ for infected vs. control cows, respectively; $P=0.58$ ). The proportion of cows with progesterone concentrations $>1 \mathrm{ng} / \mathrm{mL}$ at d 10 did not differ between groups (8/10 vs. $7 / 10$ for infected vs. control cows, respectively; $P=0.61$ ).

\section{Exosome Characterization}

Exosomes derived from cow plasma were isolated and characterized using immunoblotting NTA, transmission electron microscopy, and Western blot (Figure 1). Figure $1 \mathrm{~A}$ and $1 \mathrm{~B}$ shows size distribution and particle number for both groups and time points. No significant treatment or time point differences were observed in exosome size and particle number. Through NTA, we obtained total exosome particle number (particles per $\mathrm{mL})$ from infected $(\mathrm{n}=10)$ and noninfected $(\mathrm{n}=10)$ groups. The average exosome number of noninfected cows was $2.15 \times 10^{10}$ particles $/ \mathrm{mL}$, and the median was $2.09 \times 10^{10}$ particles $/ \mathrm{mL}$. The average exosome number of infected cows was 1.70 particles $/ \mathrm{mL}$, and the median was $1.67 \times 10^{10}$ particles $/ \mathrm{mL}$. The results of protein concentration were obtained. The average exosomal concentration of noninfected cows was 261.59 $\mu \mathrm{g} / \mathrm{mL}$, and the median was $175.15 \mu \mathrm{g} / \mathrm{mL}$. The average exosomal concentration of infected cows was $175.75 \mu \mathrm{g} / \mathrm{mL}$, and the median was $149.99 \mu \mathrm{g} / \mathrm{mL}$. Immunoblotting results show that exosome-enriched markers, flotillin 1 and tumor susceptibility gene 101 proteins, were abundant in noninfected and infected animals (representative Western blot shown in Figure 1C). Transmission electron microscopy confirmed the spherical shaped morphology of the exosomes isolated (representative vesicle shown in Figure 1D).

\section{PG Production}

Production of $\mathrm{PGE}_{2}$ and $\mathrm{PGF}_{2 \alpha}$ by epithelial cells decreased numerically in response to exosomes derived from d 10 plasma of infected cows (Figure 2A and 2B). No EXO control infected and noninfected animals did not differ at d 0 and 10 for $\mathrm{PGE}_{2}$ (Figure 2A) production. Production of $\mathrm{PGF}_{2 \alpha}$ decreased by $38 \%$ in response to plasma exosomes from cows infected on $\mathrm{d}$
10 compared with No EXO control $(P=0.03)$, and by $44 \%$ compared with noninfected cows on d $10(P=$ 0.02; Figure 2B). Stromal cell production of $\mathrm{PGE}_{2}$ (Figure $2 \mathrm{C}$ ) or $\mathrm{PGF}_{2 \alpha}$ (Figure 2D) did not differ between groups or time points. Basal production of $\mathrm{PGE}_{2}$ was higher than $\mathrm{PGF}_{2 \alpha}$ by both epithelial $(P=0.0001)$ and stromal $(P \leq 0.001)$ cell lines compared with $\mathrm{PGF}_{2 \alpha}$.

Basal $\mathrm{PGE}_{2}$ production (No EXO) by stromal cells was higher than epithelial cells $(P \leq 0.001)$. However, $\mathrm{PGF}_{2 \alpha}$ production was similar for epithelial and stromal cells. No differences were observed in the ratio of d 10:d 0 in the noninfected and infected groups for $\mathrm{PGE}_{2}$ production by epithelial and stromal cells. No differences were observed in the ratio of $\mathrm{d} 10: \mathrm{d} 0$ in the noninfected and infected groups for $\mathrm{PGF}_{2 \alpha}$ production by stromal cells; however, epithelial cell $\mathrm{PGF}_{2 \alpha}$ production was reduced when treated with exosomes of infected compared with noninfected cows $(P=0.002)$.

We considered the possibility that this response was caused by the presence of inflammation induced by plasma carryovers. Therefore, we measured IL- 6 production from culture media, and no differences were found between the groups of both cell lines (Figure 3). We also considered the likelihood of decrease in $\mathrm{PGF}_{2 \alpha}$ production by epithelial cells due to cell death caused by the treatment material, but this was not the case because no significant difference was observed in lactate dehydrogenase measurements between d 10 noninfected and d 10 infected (data not shown).

\section{DISCUSSION}

Our results highlight that circulating exosomes of uterine-infected cows significantly decrease $\mathrm{PGF}_{2 \alpha}$ production by epithelial cells but not stromal cells. Our results are similar to previous studies where cultured bovine endometrial cells were shown to produce $\mathrm{PGE}_{2}$ and $\mathrm{PGF}_{2 \alpha}$ when directly challenged with E. coli or T. pyogenes (Herath et al., 2006; Sheldon et al., 2014). Whereas, endometrial explants challenged with $E$. coli or LPS (Herath et al., 2009) have increased PGE but not PGF production. This study demonstrated that exosomes derived from plasma of infected cows produce similar changes in prostaglandin ratios as those demonstrated in in vitro cell culture systems with direct bacterial infections. This information is critical for future research investigating prostaglandin suppression mechanisms.

Uterine infection was confirmed by isolation of $T$. pyogenes and by an increased proportion of neutrophils upon endometrial cytology. Abnormal estrus cycle lengths, associated with failure of luteolysis, is one mechanism by which uterine disease may affect the probability that cows conceive (Opsomer et al., 1998). 
A

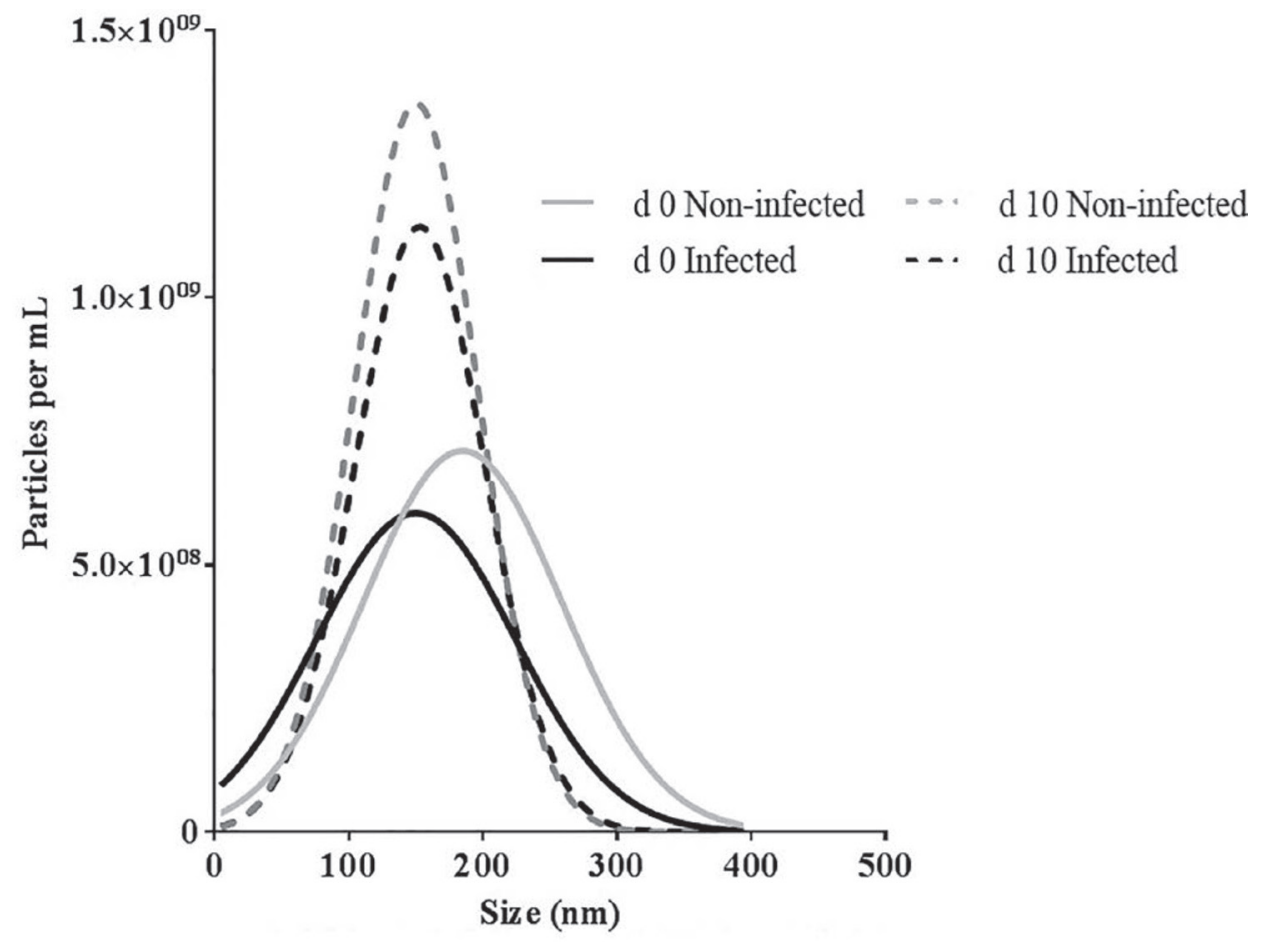

B

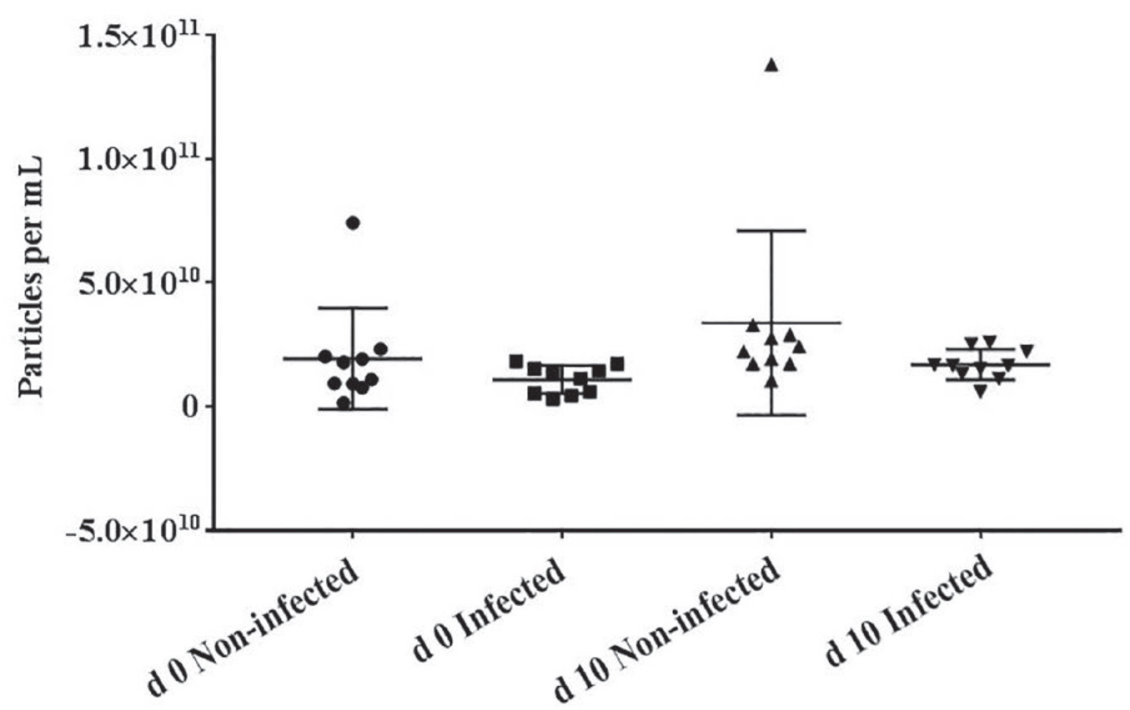

C

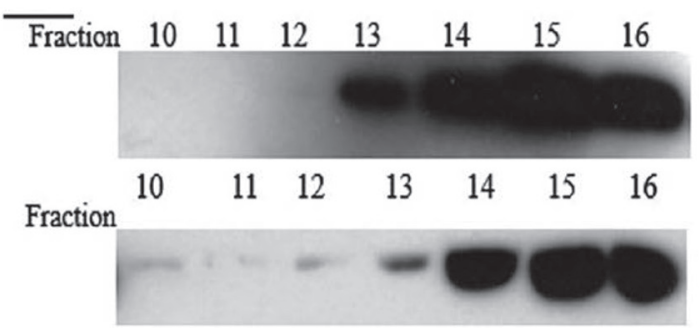

D

FLOT1

TSG101

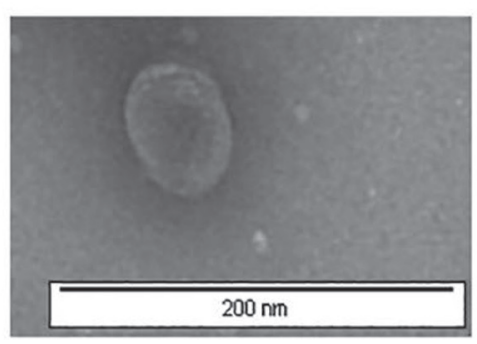

Figure 1. Exosome characterization from bovine plasma for noninfected and infected groups at d 0 and 10. (A) Particle size (nm) distribution of exosomal fractions by nanoparticle tracking analysis (NTA). (B) Particle number (particles per mL) of exosomal fractions by NTA. Bars represent 95\% confidence. (C) Representative Western blot for exosomal markers flotillin 1 (FLOT1) and tumor susceptibility gene 101 (TSG101) of exosomal fractions 10 to 16 (sample presented is d 10 infected). (D) Electron micrograph of an exosome from exosome-enriched fraction. 
Recently, it has been demonstrated that infusion of a pure culture of $T$. pyogenes into the bovine uterus results in establishment of infection in the great majority of cows (Amos et al., 2014). However, we did not detect differences in the number or size of plasma exosomes of cows that did or did not have a uterine infection in this study. Thus, the number and size of exosomes are unlikely to provide the basis of a useful diagnostic test.

Exosomes carry phospholipases, arachidonic acid, prostaglandins, leukotrienes, and enzymes involved
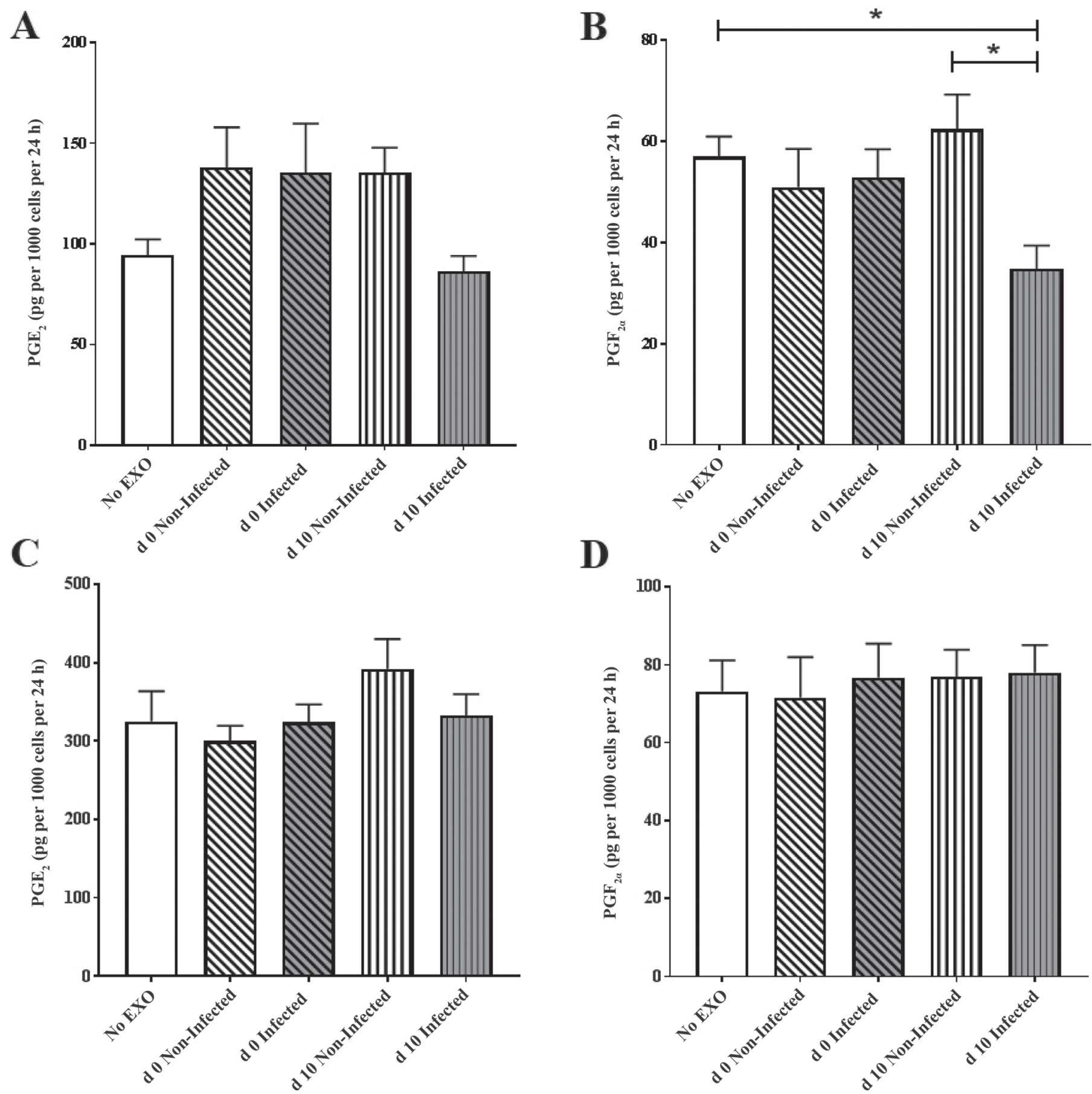

Figure 2. Prostaglandin production by epithelial [(A) prostaglandin $\mathrm{E}_{2}\left(\mathrm{PGE}_{2}\right)$ and $\left.(\mathrm{B}) \mathrm{PGF}_{2 \alpha}\right]$ and stromal $\left[(\mathrm{C}) \mathrm{PGE}_{2}\right.$ and $\left.(\mathrm{D}) \mathrm{PGF}_{2 \alpha}\right]$ cells co-incubated with exosomes derived from bovine plasma. Prostaglandin production was measured directly from media with no exosome addition (No EXO) or with the addition of exosomes derived from d 0 noninfected, d 0 infected, d 10 noninfected, or d 10 infected groups. Values are presented as mean $\pm \mathrm{SEM} ; \mathrm{n}=10 .{ }^{*} P \leq 0.05$. 
in the production of these compounds (Subra et al., 2010; Deng et al., 2013; Mitchell et al., 2016). By co-incubating epithelial and stromal endometrial cell lines with exosomes derived from plasma of uterine infected or noninfected dairy cows, we established an in vitro model of endometrium response to systemically available signals during infection. We confirm that the basal production of $\mathrm{PGE}_{2}$ was higher in stromal cells compared with epithelial cells (Fortier et al., 1988; Betts and Hansen, 1992; Danet-Desnoyers et al., 1994; Asselin et al., 1996), whereas $\mathrm{PGF}_{2 \alpha}$ was similar for epithelial and stromal cells (Betts and Hansen, 1992).

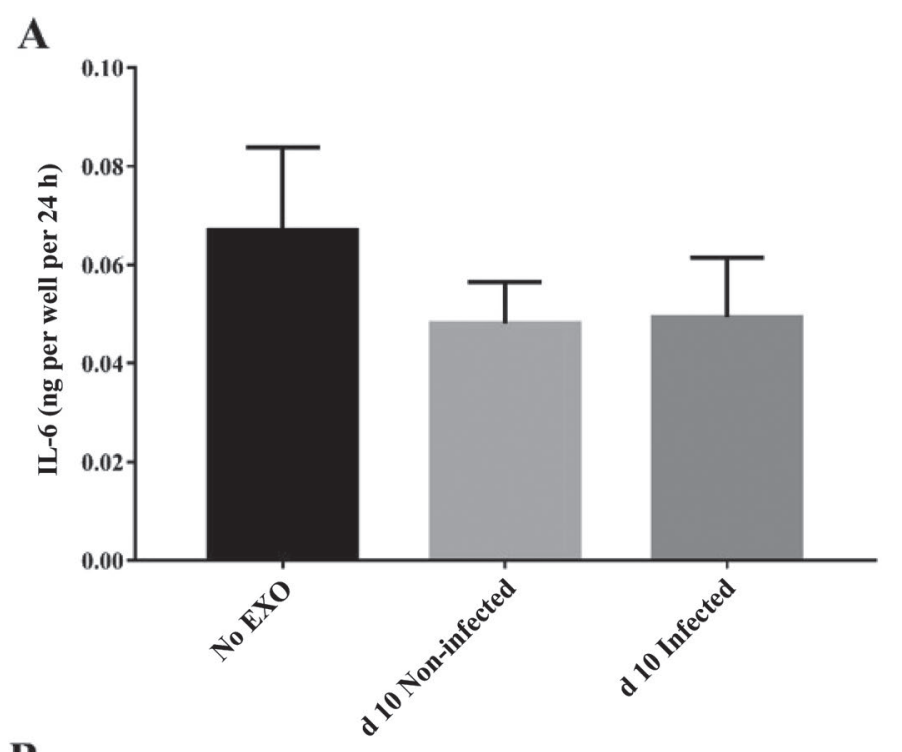

B

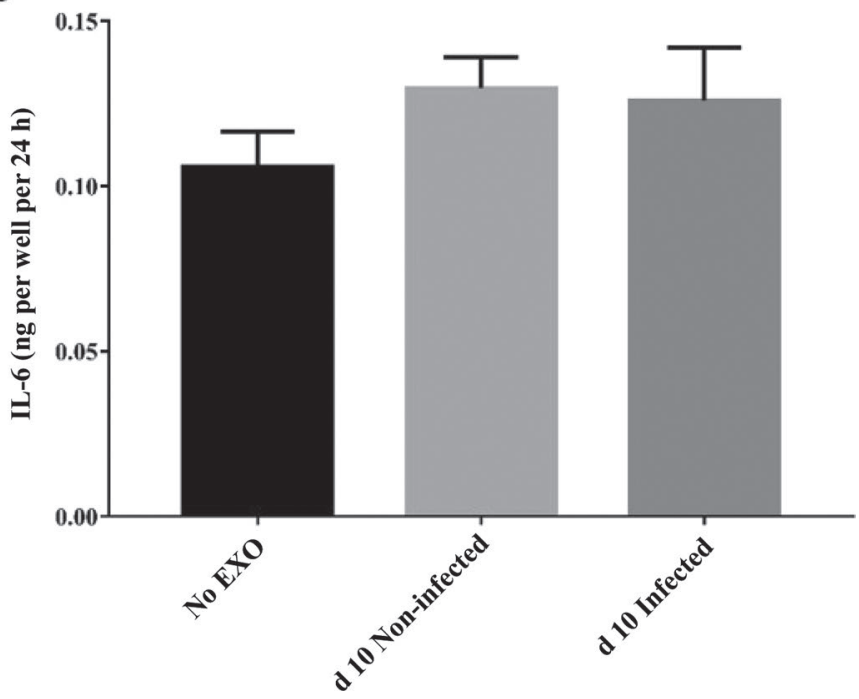

Figure 3. Production of IL-6 by endometrial cells co-incubated with exosomes derived from bovine plasma in (A) epithelial and (B) stromal cells. Production was directly measured from media with no exosome addition (No EXO) or with the addition of exosomes derived from d 10 noninfected or d 10 infected groups. Values are presented as mean $\pm \mathrm{SD} ; \mathrm{n}=10$.
Our stromal basal production of $\mathrm{PGE}_{2}$ was higher than $\mathrm{PGF}_{2 \alpha}$, which is consistent with previous papers (Fortier et al., 1988; Betts and Hansen, 1992; Kim et al., 1994; Asselin et al., 1996; Herath et al., 2009; Krishnaswamy et al., 2009a). In contrast to Krishnaswamy et al., our epithelial cells basal production for $\mathrm{PGE}_{2}$ was higher than $\mathrm{PGF}_{2 \alpha}$ (Krishnaswamy et al., 2009b), but this is consistent with other literature (Betts and Hansen, 1992; Herath et al., 2009). This variation in results can be due to several factors, such as cell lines used, cell passage number, time of storage, incubation time, and the nature of measurement method.

Exosome numbers did not significantly differ between the groups. Thus, a simple, nonspecific diagnostic could not be based on this property. Under other conditions, infection-like stressors can upregulate exosome release by more than 2 -fold, as well as alter cargo protein composition (Silverman et al., 2010). It seems likely that the best opportunity for a diagnostic or prognostic test would be in determining specific differences in exosome cargo obtained under healthy and infected conditions. Circulating exosomes reflect secretion from several tissues within the whole body. The overall change in the property of exosomes with infection (causing decreased $\mathrm{PGF}_{2 \alpha}$ secretion by endometrial epithelial cells) may be enhanced by the separation of isolation of exosomes originating from the endometrium alone. If endometrial exosomes were isolated with confidence, we could then better study the specific cargo related to specifically endometrial conditions. This may then allow the development of a useful diagnostic using the biomarkers identified within the content of these specific exosomes. The utility of evaluating exosome cargo and its importance is underscored by the fact that infectious particles contained within exosomes can be 10-fold more infectious on a particle basis than cell-free infectious particles (Wiley and Gummuluru, 2006).

Extracellular vesicles, including exosomes, are known to participate in the intercellular communication, paracrine and endocrine signaling. A recent study demonstrated that the inhibition of PGE receptor, cyclooxygenase-2, and PGE synthase would increase EV production by mammary epithelial cells (Lin et al., 2017). Circulating exosomes might carry signals to decrease prostaglandin production during an infection (e.g., by actions on steroidal hormones or increasing the expression of estrogen receptors).

In conclusion, the number or size of exosomes in plasma from cows that were or were not infected following intrauterine challenge with $T$. pyogenes did not differ. However, plasma exosomes derived from infected cows significantly reduced $\mathrm{PGF}_{2 \alpha}$ production by epithelial cells in culture. It is possible that identification of endometrium-specific exosomal cargos from plasma 
of infected dairy cows may provide a pathway for the development of a sensitive, specific, rapid, and costeffective diagnostic tools for uterine disease in dairy cattle.

\section{ACKNOWLEDGMENTS}

Microbiology for this study was undertaken by Libby Graham and Niki Sowerby of Cognosco, Anexa FVC (Morrinsville, New Zealand). Animal procedures including bleeding, transrectal ultrasonography, uterine infusion, and uterine sampling were undertaken by Stu Morgan (DairyNZ, Hamilton, New Zealand), Charlotte Reed (DairyNZ), Olivia Jordan (DairyNZ), and Marty Berg (McGrath, USA). This study was funded by a partnership (DRCX1302) between the New Zealand Ministry for Primary Industries and Employment (Wellington, New Zealand) and New Zealand dairy farmers through DairyNZ Inc. (Hamilton, New Zealand), as well as by the Australian government through the Australian Research Council (Canberra, ACT, Australia).

\section{REFERENCES}

Amos, M. R., G. D. Healey, R. J. Goldstone, S. M. Mahan, A. Duvel, H. J. Schuberth, O. Sandra, P. Zieger, I. Dieuzy-Labaye, D. G. Smith, and I. M. Sheldon. 2014. Differential endometrial cell sensitivity to a cholesterol-dependent cytolysin links Trueperella pyogenes to uterine disease in cattle. Biol. Reprod. 90:54.

Arosh, J. A., J. Parent, P. Chapdelaine, J. Sirois, and M. A. Fortier. 2002. Expression of cyclooxygenases 1 and 2 and prostaglandin E synthase in bovine endometrial tissue during the estrous cycle. Biol. Reprod. 67:161-169.

Asselin, E., A. K. Goff, H. Bergeron, and M. A. Fortier. 1996. Influence of sex steroids on the production of prostaglandins F2 alpha and E2 and response to oxytocin in cultured epithelial and stromal cells of the bovine endometrium. Biol. Reprod. 54:371-379.

Bello, N. M., J. P. Steibel, and J. R. Pursley. 2006. Optimizing ovulation to first GnRH improved outcomes to each hormonal injection of ovsynch in lactating dairy cows. J. Dairy Sci. 89:3413-3424.

Betts, J. G., and P. J. Hansen. 1992. Regulation of prostaglandin secretion from epithelial and stromal cells of the bovine endometrium by interleukin-1 beta, interleukin-2, granulocyte-macrophage colony stimulating factor and tumor necrosis factor-alpha. Life Sci. 51:1171-1176.

Crookenden, M. A., C. G. Walker, H. Peiris, Y. Koh, A. Heiser, J. J. Loor, K. M. Moyes, A. Murray, V. S. R. Dukkipati, J. K. Kay, S. Meier, J. R. Roche, and M. D. Mitchell. 2016. Short communication: Proteins from circulating exosomes represent metabolic state in transition dairy cows. J. Dairy Sci. 99:7661-7668.

Danet-Desnoyers, G., C. Wetzels, and W. W. Thatcher. 1994. Natural and recombinant bovine interferon tau regulate basal and oxytocin-induced secretion of prostaglandins F2 alpha and E2 by epithelial cells and stromal cells in the endometrium. Reprod. Fertil. Dev. 6:193-202.

de Boer, M. W., S. J. LeBlanc, J. Dubuc, S. Meier, W. Heuwieser, S. Arlt, R. O. Gilbert, and S. McDougall. 2014. Invited review: Systematic review of diagnostic tests for reproductive-tract infection and inflammation in dairy cows. J. Dairy Sci. 97:3983-3999.

Del Vecchio, R. P., D. J. Matsas, S. Fortin, D. P. Sponenberg, and G. S. Lewis. 1994. Spontaneous uterine infections are associated with elevated prostaglandin $\mathrm{F}(2)$ alpha metabolite concentrations in postpartum dairy cows. Theriogenology 41:413-421.
Deng, Z. B., X. Zhuang, S. Ju, X. Xiang, J. Mu, Y. Liu, H. Jiang, L. Zhang, J. Mobley, C. McClain, W. Feng, W. Grizzle, J. Yan, D. Miller, M. Kronenberg, and H. G. Zhang. 2013. Exosome-like nanoparticles from intestinal mucosal cells carry prostaglandin E2 and suppress activation of liver NKT cells. J. Immunol. 190:35793589 .

Fortier, M. A., L. A. Guilbault, and F. Grasso. 1988. Specific properties of epithelial and stromal cells from the endometrium of cows. J. Reprod. Fertil. 83:239-248.

Franzen, C. A., P. E. Simms, A. F. Van Huis, K. E. Foreman, P. C. Kuo, and G. N. Gupta. 2014. Characterization of uptake and internalization of exosomes by bladder cancer cells. BioMed Res. Int. 2014:619829.

Garnsworthy, P. C., K. D. Sinclair, and R. Webb. 2008. Integration of physiological mechanisms that influence fertility in dairy cows. Animal 2:1144-1152.

Herath, S., D. P. Fischer, D. Werling, E. J. Williams, S. T. Lilly, H. Dobson, C. E. Bryant, and I. M. Sheldon. 2006. Expression and function of toll-like receptor 4 in bovine endometrium. Endocrinology 147:562-570.

Herath, S., S. T. Lilly, D. P. Fischer, E. J. Williams, H. Dobson, C. E. Bryant, and I. M. Sheldon. 2009. Bacterial lipopolysaccharide induces an endocrine switch from prostaglandin F2alpha to prostaglandin E2 in bovine endometrium. Endocrinology 150:1912-1920.

Inchaisri, C., R. Jorritsma, P. L. Vos, G. C. van der Weijden, and H. Hogeveen. 2010. Economic consequences of reproductive performance in dairy cattle. Theriogenology 74:835-846.

Kasimanickam, R., T. F. Duffield, R. A. Foster, C. J. Gartley, K. E. Leslie, J. S. Walton, and W. H. Johnson. 2004. Endometrial cytology and ultrasonography for the detection of subclinical endometritis in postpartum dairy cows. Theriogenology 62:9-23.

Kim, J. J., P. A. Quinn, and M. A. Fortier. 1994. Ureaplasma diversum infection in vitro alters prostaglandin E2 and prostaglandin F2a production by bovine endometrial cells without affecting cell viability. Infect. Immun. 62:1528-1533.

King, H. W., M. Z. Michael, and J. M. Gleadle. 2012. Hypoxic enhancement of exosome release by breast cancer cells. BMC Cancer 12:421.

Krishnaswamy, N., P. Chapdelaine, J. P. Tremblay, and M. A. Fortier. 2009a. Development and characterization of a simian virus 40 immortalized bovine endometrial stromal cell line. Endocrinology 150:485-491.

Krishnaswamy, N., G. Danyod, P. Chapdelaine, and M. A. Fortier. 2009b. Oxytocin receptor down-regulation is not necessary for reducing oxytocin-induced prostaglandin $\mathrm{F} 2 \alpha$ accumulation by interferon- $\tau$ in a bovine endometrial epithelial cell line. Endocrinology 150:897-905.

Lin, M.-C., S.-Y. Chen, H.-M. Tsai, P.-L. He, Y.-C. Lin, H. Herschman, and H.-J. Li. 2017. PGE2/EP4 signaling controls the transfer of the mammary stem cell state by lipid rafts in extracellular vesicles. Stem Cells 35:425-444.

Lucy, M. C. 2001. Reproductive loss in high-producing dairy cattle: Where will it end? J. Dairy Sci. 84:1277-1293.

McDougall, S., H. Hussein, D. Aberdein, K. Buckle, J. Roche, C Burke, M. Mitchell, and S. Meier. 2011. Relationships between cytology, bacteriology and vaginal discharge scores and reproductive performance in dairy cattle. Theriogenology 76:229-240.

Mitchell, M. D., K. Scholz-Romero, S. Reed, H. N. Peiris, Y. Q. Koh, S. Meier, C. G. Walker, C. R. Burke, J. R. Roche, G. Rice, and C. Salomon. 2016. Plasma exosome profiles from dairy cows with divergent fertility phenotypes. J. Dairy Sci. 99:7590-7601.

Opsomer, G., M. Coryn, H. Deluyker, and A. de Kruif. 1998. An analysis of ovarian dysfunction in high yielding dairy cows after calving based on progesterone profiles. Reprod. Domest. Anim. 33:193-204.

Raposo, G., and W. Stoorvogel. 2013. Extracellular vesicles: Exosomes, microvesicles, and friends. J. Cell Biol. 200:373-383.

Ribeiro, E. S., F. S. Lima, L. F. Greco, R. S. Bisinotto, A. P. Monteiro, M. Favoreto, H. Ayres, R. S. Marsola, N. Martinez, W. W. Thatcher, and J. E. Santos. 2013. Prevalence of periparturient 
diseases and effects on fertility of seasonally calving grazing dairy cows supplemented with concentrates. J. Dairy Sci. 96:5682-5697.

Roche, J. R., C. R. Burke, S. Meier, and C. G. Walker. 2011. Nutrition $\times$ reproduction interaction in pasture-based systems: Is nutrition a factor in reproductive failure? Anim. Prod. Sci. 51:1045-1066.

Roche, J. R., P. G. Dillon, C. R. Stockdale, L. H. Baumgard, and M. J. VanBaale. 2004. Relationships among international body condition scoring systems. J. Dairy Sci. 87:3076-3079.

Sabapatha, A., C. Gercel-Taylor, and D. D. Taylor. 2006. Specific isolation of placenta-derived exosomes from the circulation of pregnant women and their immunoregulatory consequences. Am. J. Reprod. Immunol. 56:345-355.

Sheldon, I. M., J. Cronin, L. Goetze, G. Donofrio, and H. J. Schuberth. 2009. Defining postpartum uterine disease and the mechanisms of infection and immunity in the female reproductive tract in cattle. Biol. Reprod. 81:1025-1032.

Sheldon, I. M., J. G. Cronin, G. D. Healey, C. Gabler, W. Heuwieser, D. Streyl, J. J. Bromfield, A. Miyamoto, C. Fergani, and H. Dobson. 2014. Innate immunity and inflammation of the bovine female reproductive tract in health and disease. Reproduction 148:R41R51.

Sheldon, I. M., D. E. Noakes, A. N. Rycroft, D. U. Pfeiffer, and H. Dobson. 2002. Influence of uterine bacterial contamination af- ter parturition on ovarian dominant follicle selection and follicle growth and function in cattle. Reproduction 123:837-845.

Silverman, J. M., J. Clos, C. C. de'Oliveira, O. Shirvani, Y. Fang, C. Wang, L. J. Foster, and N. E. Reiner. 2010. An exosome-based secretion pathway is responsible for protein export from Leishmania and communication with macrophages. J. Cell Sci. 123:842-852.

Sohel, M. M., M. Hoelker, S. S. Noferesti, D. Salilew-Wondim, E. Tholen, C. Looft, F. Rings, M. J. Uddin, T. E. Spencer, K. Schellander, and D. Tesfaye. 2013. Exosomal and non-exosomal transport of extra-cellular microRNAs in follicular fluid: Implications for bovine oocyte developmental competence. PLoS One 8:e78505.

Subra, C., D. Grand, K. Laulagnier, A. Stella, G. Lambeau, M. Paillasse, P. De Medina, B. Monsarrat, B. Perret, S. Silvente-Poirot, M. Poirot, and M. Record. 2010. Exosomes account for vesiclemediated transcellular transport of activatable phospholipases and prostaglandins. J. Lipid Res. 51:2105-2120.

Wiley, R. D., and S. Gummuluru. 2006. Immature dendritic cell-derived exosomes can mediate HIV-1 trans infection. Proc. Natl. Acad. Sci. USA 103:738-743. 